\title{
Harmonic Contribution Analysis of Electric Arc Furnace by Using Spectrogram
}

\author{
M. H. Jopri' ${ }^{1}$, A. R. Abdullah ${ }^{2}$, M. Manap ${ }^{3}$, T. Sutikno ${ }^{4}$, M. R. Ab. Ghani', \\ ${ }^{1,3}$ Center for Robotics and Industrial Automation (CeRIA), Faculty of Engineering Technology, Universiti Teknikal \\ Malaysia Melaka (UTeM), Malaysia \\ ${ }^{2,5}$ CeRIA, Faculty of Electrical Engineering, UTeM, Malaysia \\ ${ }^{4}$ Department of Electrical Engineering, Universitas Ahmad Dahlan (UAD), Yogyakarta, Indonesia
}

\begin{tabular}{lll}
\hline \hline Article Info & ABSTRACT \\
\cline { 1 - 2 } Article history: & $\begin{array}{l}\text { In this paper, spectrogram, a fast and accurate technique is introduced for the } \\
\text { analysis of the contribution. Based on a rule-based classifier and the } \\
\text { threshold settings that referred to the IEEE Standard 1159 2009, the analysis } \\
\text { of the harmonic and interharmonic contribution of EAF are carried out } \\
\text { Revised Apr 21, 2018 } \\
\text { Accepted May 05, 2018 }\end{array}$ & $\begin{array}{l}\text { successfully. Moreover, the impact of contribution is measured using total } \\
\text { harmonic distortion (THD) and total non-harmonic distortion (TnHD). In } \\
\text { addition, spectrogram also gives 100 percent correct detection and able to } \\
\text { analyze the contribution impact. It is proven that the proposed method is } \\
\text { accurate, fast and cost efficient for analyzing the impact of harmonic and } \\
\text { interharmonic of EAF. }\end{array}$ \\
$\begin{array}{l}\text { Electric arc furnace } \\
\text { Harmonic }\end{array}$ &
\end{tabular}

Interharmonic

Spectrogram

Copyright $@ 2018$ Institute of Advanced Engineering and Science. All rights reserved.

Corresponding Author:

M. H. Jopri,

Center for Robotics and Industrial Automation (CeRIA),

Faculty of Engineering Technology,

Universiti Teknikal Malaysia Melaka (UTeM), Malaysia.

Email: hatta@utem.edu.my

\section{INTRODUCTION}

Presently electric arc furnace (EAF) is extensively used in iron and steel industry due to the increase in demand for iron such as in the vehicle industry.[1]. Electric arc furnace is used for melting alloys such as steel at high melting point [2]. Electrical energy is converted into thermal energy by electric arc furnaces during the melting of raw materials. Serious power quality problems occurred during the melting process whereas the random property of arc melting process and the control system are the fundamental reasons for the electrical and thermal dynamics [3]. The EAFs create the power quality issues such as unbalanced voltages and currents, voltage flickers as well as odd and even harmonics caused by the time-variant and nonlinear loads [4]. The cause of harmonics is predominantly identified with the non-linear voltage-current characteristic of the arc. There is no current standard for identifying the dominant harmonic disturbances [5], [6].

The effect of the harmonic distortion caused several problems in electrical power systems, such as influence operation of devices, non-durable equipment, and increase losses in transmission and distribution networks, overvoltage and overcurrent [2]. As an EAF is a large source of harmonics, causes voltage-current distortion which is a major power quality issue that influences connected load operation in the electric network. Hence, harmonic analysis of EAF has attracted the attention of researchers to solve these power quality issues pertaining to EAF [6]. Harmonics can be analyzed using frequency, time and time-frequency domain methods [7]. The details of the concept and analytical of these methods are briefly explained in this 
paper. There are several signal processing based method approaches have been proposed in harmonic detection analysis in order to assess the power quality issues [8].

A frequency-domain analysis method has been introduced called Fourier Transform (FT) [1]. The FT technique is usually used for the spectral and harmonics analysis [9].The Fast Fourier Transform (FFT) is a reasonable approach for stationary signal, but it loses accuracy under time fluctuating frequency conditions and furthermore have picket and fence problems [10]. The short time Fourier transform (STFT) has overcome the deficiencies of FT by employing a time-frequency window to localize transient in a signal [9]. The Wavelet Transform (DWT) has been proposed by researchers to overcome the fixed resolution problem of STFT for analyzing power quality disturbances. Wavelet-Transform (WT) have been developed as timefrequency domain and it is very good in detecting the beginning of the transients. However, Wavelet Transform have a drawback which is incapable to give accurate result under a noise condition because of poor frequency resolution [8], [11]. A modified version of the STFT known as S-transform (ST) has been proposed for the recognition of power quality disturbance. S-transform is a superior tool to analyze transient disturbances [11]. However, the detection ability of ST also degrades in analyzing some non-stationary transient disturbances [9].

By concerning the mentioned limitations, this paper proposes time-frequency domain of harmonic analysis using spectrogram. The spectrogram is the squared magnitude of the STFT [16]. The point of interest is it involves a compromise between time resolution and frequency resolution. It is mean that a longer window provides less localization in time and more discrimination in frequency [12]. Therefore, it is an effective analyzing technique for voltage variation and capable to give the high precision of the result [11].

\section{RESEARCH METHOD}

\subsection{Electric Arc Furnace}

Large and continuously randomly varying nonlinear loads. The furnace arc impedance varies randomly and extremely asymmetrical since the carbon electrodes in contact with iron have dissimilar impedances between the positive and negative flows of current. The three-phase EAF model developed in Simulink is shown in Figure 1.

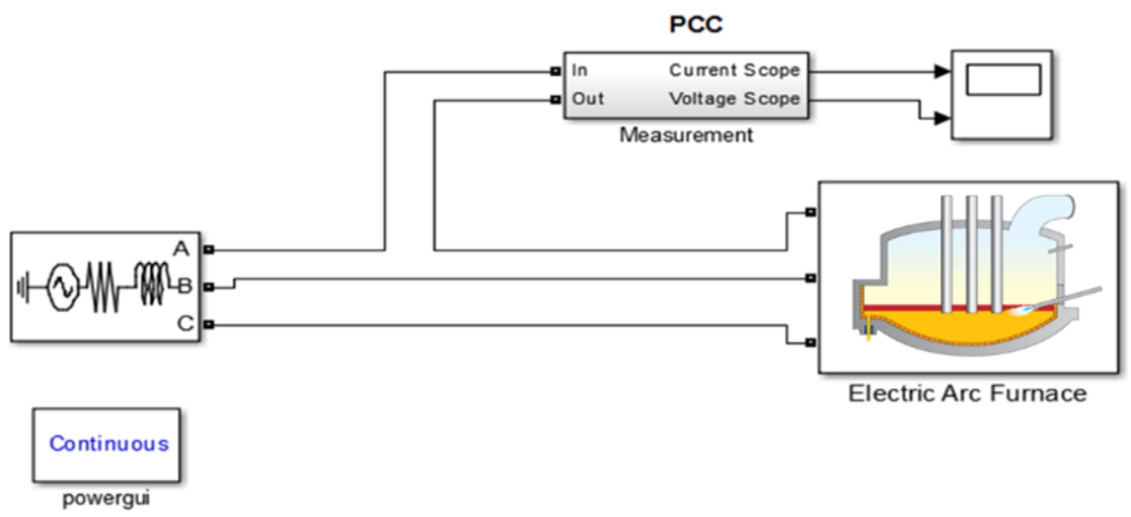

Figure 1. Electric arc furnace model

A controlled voltage source with the resistive and inductive network is used to couple the generated flicker disturbance to a given phase of the power system line. For a three-phase system, three sets of the controlled voltage source and resistive and inductive networks are required. The electric arc furnace model uses a hyperbolic model [13] defined in Equation 1, where Vat is the arc length threshold voltage, $i$ is the phase current, $\mathrm{C}$ is the arc power, and $\mathrm{D}$ is the arc current

$$
v(i)=\left(V_{a t}+\frac{C}{D+|i|}\right) \operatorname{sign}(i)
$$

The effect of voltage flicker is determined by the threshold voltage shown in Equation (2), where $V_{a t 0}$ is the base reference voltage when there is no arc activity, $m$ is the modulation index, and $\omega f$ is the flicker frequency.

$$
V_{a t}(t)=V_{a t 0}\left[1+m \cdot \sin \left(\omega_{f} t\right)\right]
$$


The EAF model is modeled by using the MATLAB sinusoidal and function block and as displayed in Figure 2. To execute the simulation, the sinusoidal block frequency is set at $55.3 \mathrm{rad} / \mathrm{sec}$, which is approximately $8.8 \mathrm{~Hz}$. Whereby, this is the frequency that can cause the flickering effect and causes inconvenience to the human eye. The $\mathrm{C}$ value is $19 \mathrm{~kW}$, while $\mathrm{D}$ is fixed at $5 \mathrm{kA}$ and the threshold voltage is $200 \mathrm{~V}$ [13]. The model consists of 400V, 1MVA and $50 \mathrm{~Hz}$.

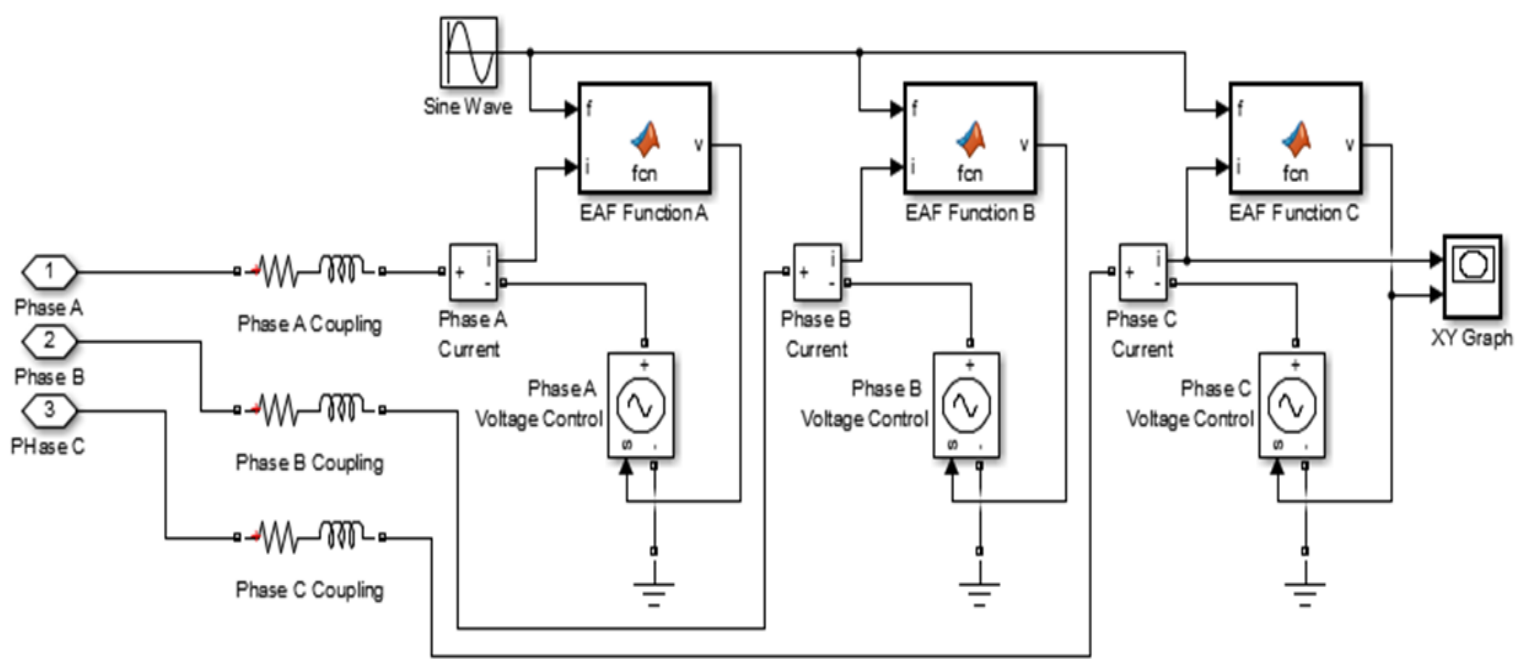

Figure 2. EAF subsystem block

\subsection{Harmonic Signal Analysis}

In the harmonic signal detection, there are four basic stages. The first stage is Time-Frequency Representation (TFR), whereas normalization of the measured signal is performed. The second stage, the signal parameters parameterization will be obtained in this. The third stage, with refer to the IEEE Std. 11592009 , the signal characterization is implemented and the detection of the harmonic signal is the final stage of harmonic signal analysis.

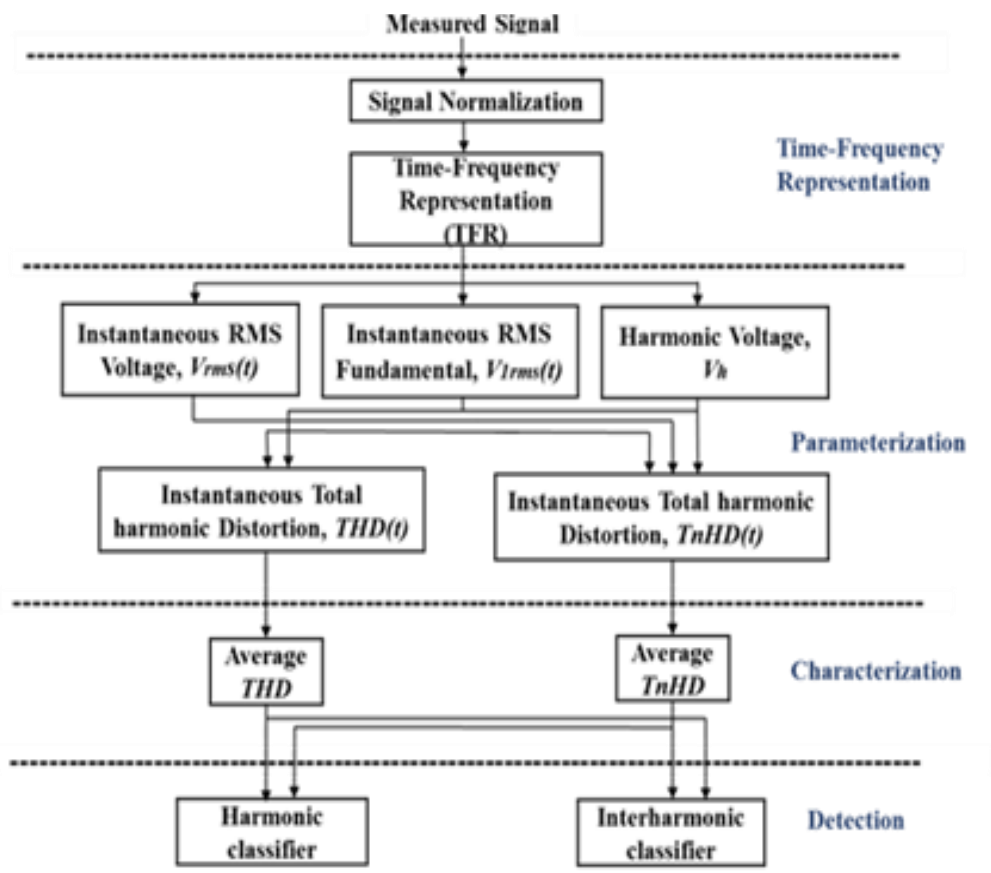

Figure 3. The process of harmonic signal analysis 


\subsection{Spectrogram}

The spectrogram is one of the time-frequency representations (TFR) that represents a three dimensional of the signal energy with respect to time and frequency and it is obtained by squared modulus of the STFT. This method generally reflects how frequency content changes over the time. A smaller window size used to create a better time resolution, yet it correspondingly reduces the frequency resolution and it mathematically expressed as [14], [15], [20]:

$$
P_{x}(t, f)=\left|\int_{-\infty}^{\infty} x(\tau) w(\tau-t) e^{-j 2 \pi f t} d \tau\right|^{2}
$$

Where $x(\tau)$ is the input signal and $w(t)$ is the observation window.

In this research, Hanning window is selected because of its lower peak side lope which has a small impact on various frequencies around the fundamental value which is $50 \mathrm{~Hz}$.

\subsection{Signal Classification}

The rule-based classifier is a is a deterministic grouping technique that utilized as a part of genuine application especially in signal classification. The deployment of rule-based classifier base on Equation 4 and 5 [14], [15],[18].

$$
\begin{aligned}
& T H D_{\text {ave }}>T n H D_{\text {thres }} \text { and } T n H D_{\text {ave }}<T n H D_{\text {thres }} \\
& T n H D_{\text {ave }}>=T n H D_{\text {thres }} \text { and } T H D_{\text {ave }}<T n H D_{\text {thres }}
\end{aligned}
$$

The existence of harmonic and interharmonic components distinguished by THD and TnHD indices, respectively. Furthermore, the implementation of signal classification plainly shows in Figure 4 . The limitation of the threshold is based on IEEE std. 1159-2009 [19].

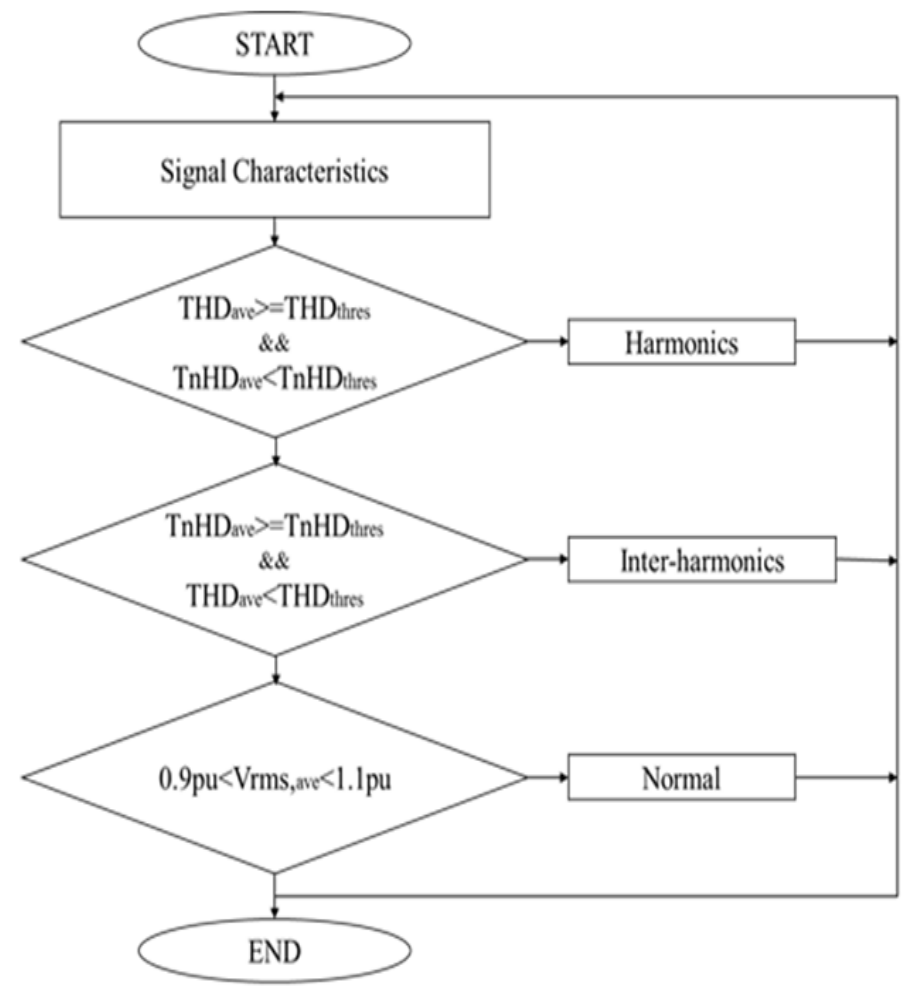

Figure 4. Flow chart of signal classification

\section{RESULTS AND ANALYSIS}

In this section, it is explained and discuss comprehensively the results of research. Figure 5(a) demonstrates the sample of the instantaneous waveform of measured voltage and current at the PCC. According to the IEEE Std 519-2014, the measurement window width should be minimum of 10 cycles and 
must consider harmonic components up to $50^{\text {th }}$ order. With refer to the IEC $61000-4-7$, a method based on the grouping concept of Harmonic Groups and Interharmonic Groups, minimum of $5 \mathrm{~Hz}$ frequency resolution is used in this study. Possibly the greatest challenge pertaining interharmonics is on the low-frequency and is is necessary to examine the model and analysis technique due to determine the applicability to harmonics at a frequency below the fundamental frequency. The TFR of voltage and current are illustrating in Figure 5(b) and Figure 5(c). Nevertheless, using the spectrogram the harmonic and interharmonic components for voltage signal were distinguished from $75 \mathrm{~Hz}$ up to $975 \mathrm{~Hz}$. In the meantime, the harmonic and interharmonic components for current signal exist between $100 \mathrm{~Hz}$ to $625 \mathrm{~Hz}$. To measure the distortion impact onto the system, the harmonic and interharmonic indices which are $\operatorname{THD}(t)$ and $\operatorname{Tn} H D(t)$ are introduced. These indices are useful in identifying and to distinguish the harmonic and interharmonic impact in the system.
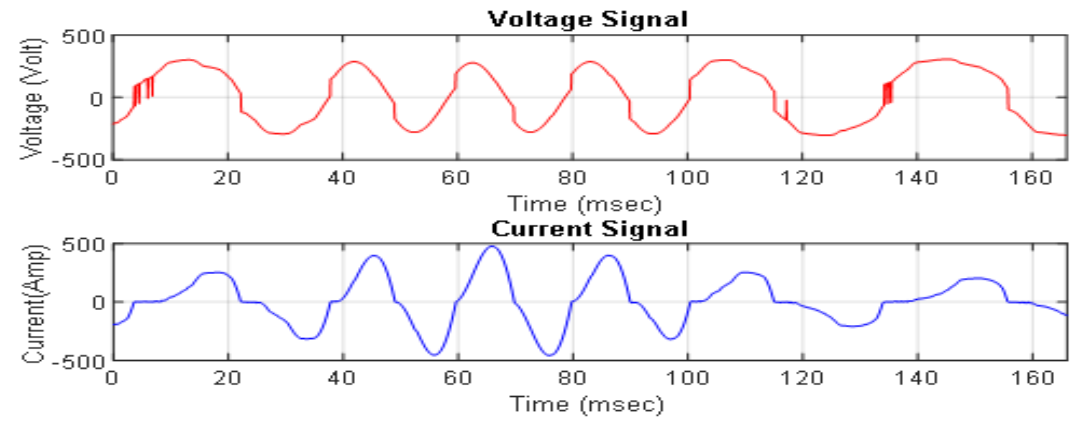

(a)

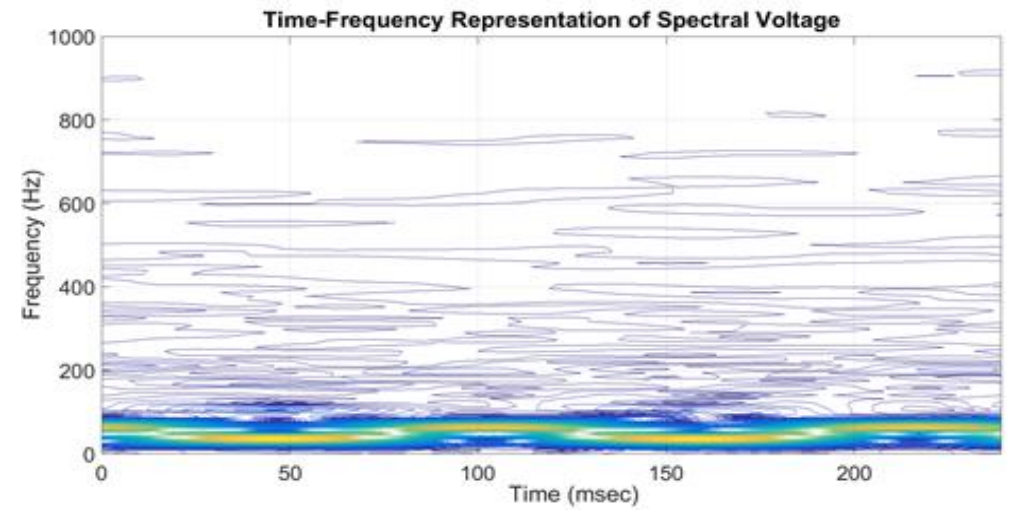

(b)

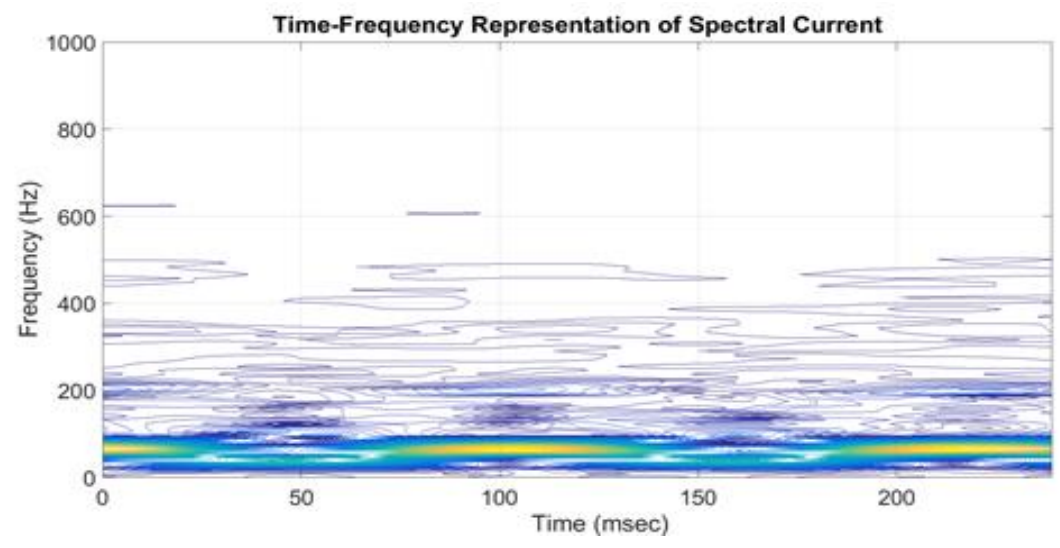

(c)

Figure 5. (a) Instantaneous voltage and current waveform at PCC, (b) TFR of the voltage signal, (c) TFR of the current signal 
The harmonic and interharmonic indices are calculated using signal parameters that were obtained from the TFR of voltage and current. Figure 6(a) depicts the $T H D(t)$ and $T n H D(t)$ of the voltage signal that were obtained from the spectrogram analysis. As can be understood from the figure, the $T H D_{V}(t)$ is in the range of zero percent to 10 percent, meanwhile, the $T n H D_{V}(t)$ value varies from 10 percent to 70 percent, respectively. In the meantime, Figure 6(b) shows that the instantaneous $T H D_{I}(t)$ and $T n H D_{I}(t)$ for the current signal which varies between 15 percent to 20 percent and 20 percent to 80 percent, correspondingly. According to the IEEE Standard 519-2014, any buses or PCC with a nominal voltage less than $1000 \mathrm{~V}$, the limits may allow $8 \% T H D_{V}$ and $5 \%$ individual voltage harmonic amplitude. It is shown that the $T H D_{V}$ has exceeded the standard limit values and the harmonic compensator is required due to improve the power quality. The 3-phase EAF has generated more harmonic distortion as the EAF does not has ground return and also using star connection for the three arc and during unbalanced condition which is in meltdown process, it will cause the harmonic and interharmonic components multiplicity generated.
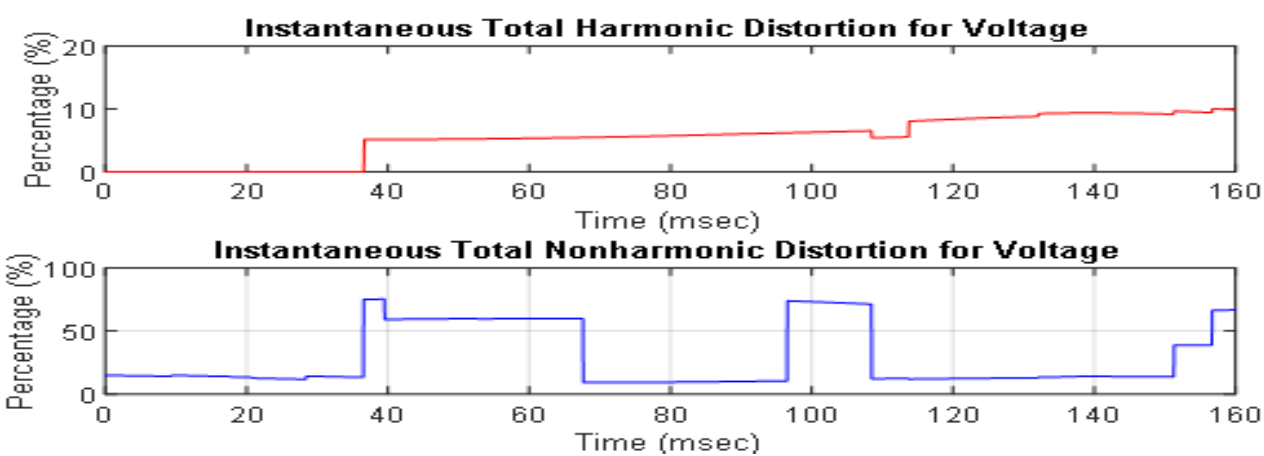

(a)
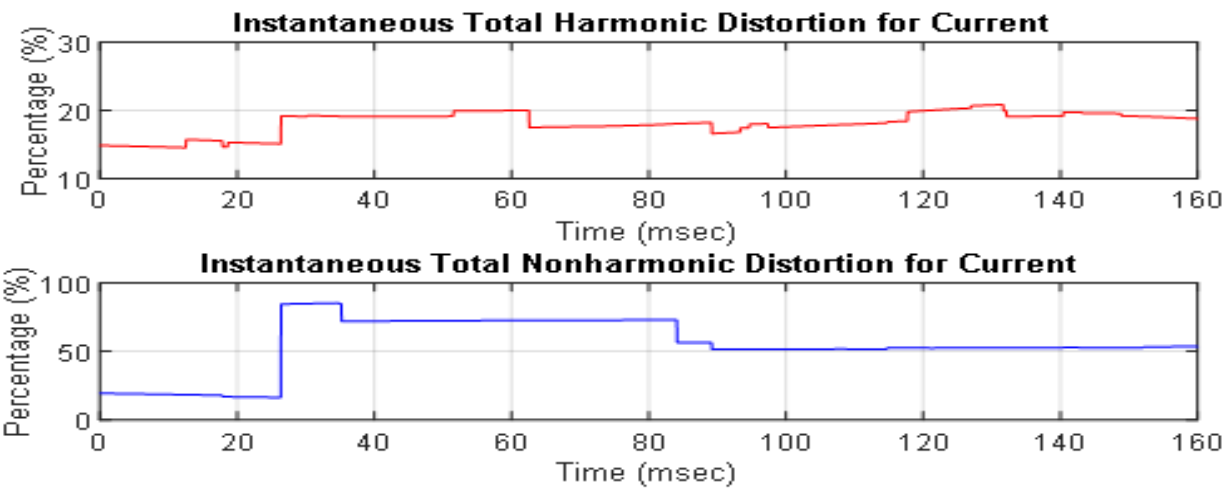

(b)

Figure 6. (a) $T H D_{V}(t)$ and $T n H D_{v}(t)$, (b) $T H D_{I}(t)$ and (d) $T n H D_{I}(t)$

For a better understanding of the harmonic and interharmonic contribution of electric arc furnace in the system, a distribution of voltage and current harmonic and interharmonic components are obtained and observed from TFR. This is done by considering all integer harmonics up to $50^{\text {th }}$ and interharmonic components with a minimum resolution of $5 \mathrm{~Hz}$, it is clearly shown that the voltage signal comprises a large number of harmonic and interharmonic components compare to the current signal. Figure 7(a) shows the harmonic and interharmonic distribution of voltage. The are 16 voltage harmonic components while 13 voltage interharmonic components are distinguished in the voltage signal. Meanwhile, Figure 7(b) depicts 5 current harmonic components and 7 interharmonic components. It is observed that the interharmonic components dominantly in the current signal. However, in the voltage signal, the number of harmonic is greater than the interharmonic component. As can be seen from Figure 7(c), the contribution of harmonic and interharmonic of EAF shows that the EAF is considered a voltage harmonic and interharmonic source as well as discussed in [4],[7]. Establishing EAF model accurately is an important prerequisite for determining the impact of its harmonic contribution to the system. Using this model and the proposed method, it is observed that the analysis of harmonic and interharmonic contribution can be defined significantly. 


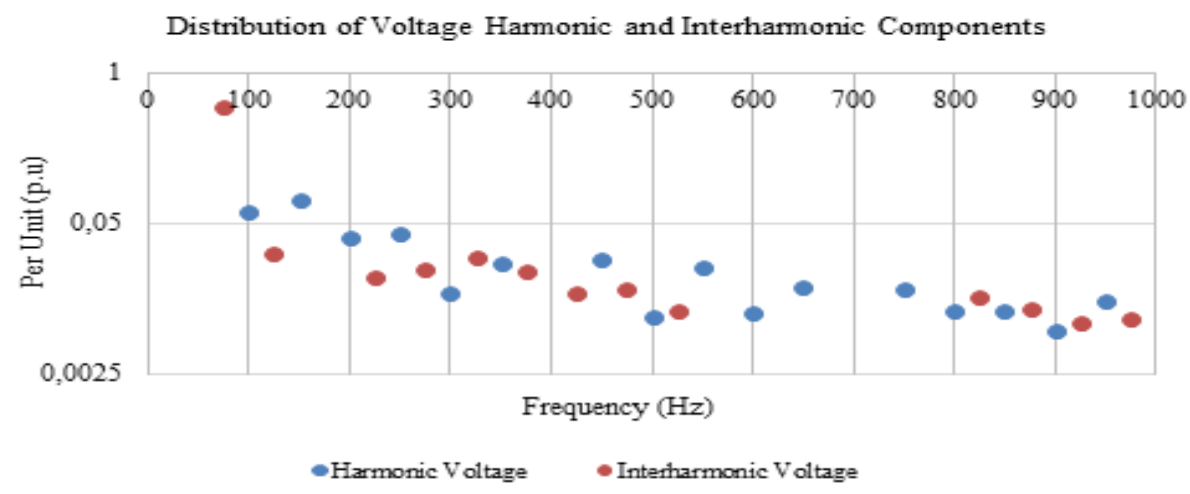

(a)

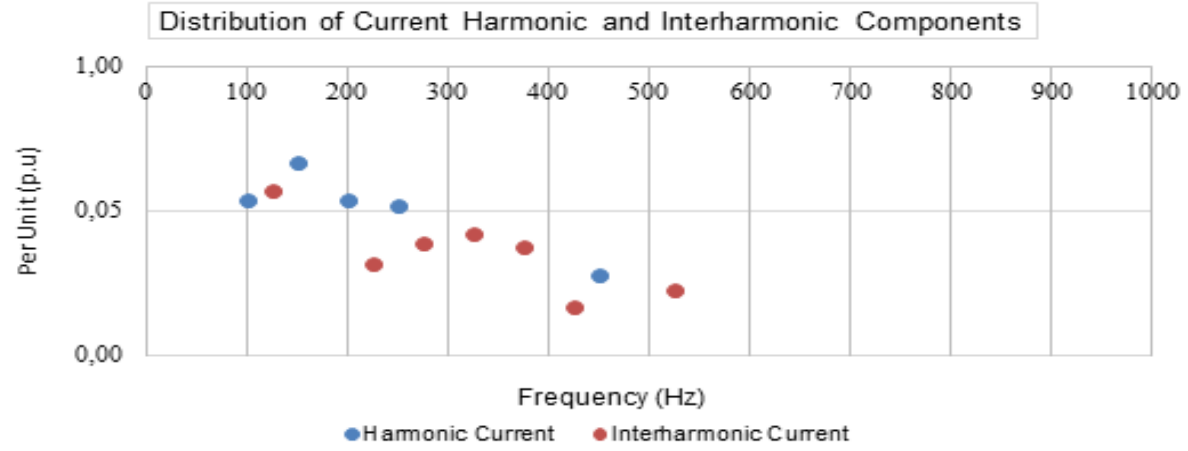

(b)

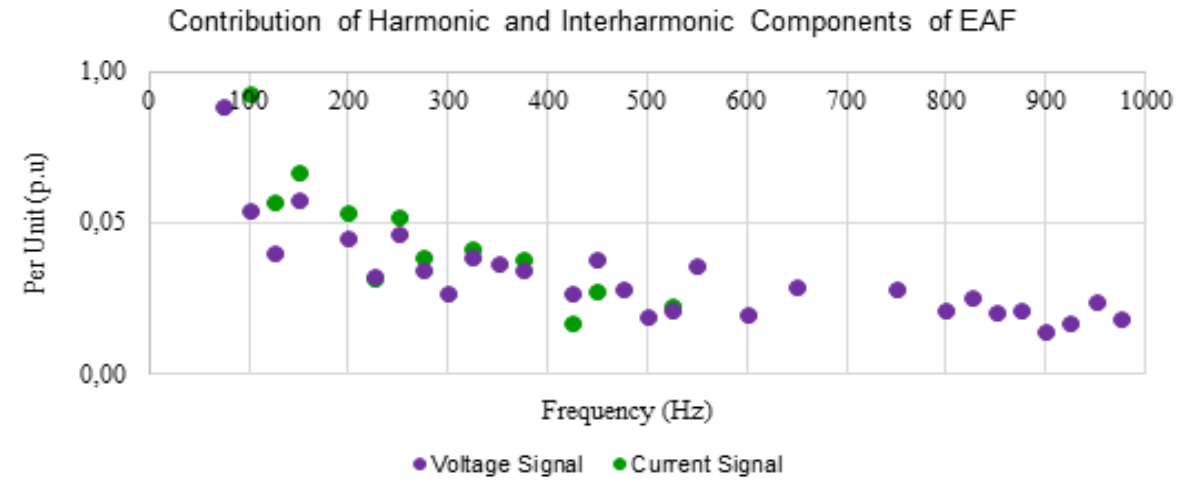

(c)

Figure 7. (a) Distribution of EAF Current Harmonic and Interharmonic Components, (b) Distribution of EAF Voltage Harmonic and Interharmonic Components, (c) Contribution of Harmonic and Interharmonic Components by EAF

\section{CONCLUSION}

The analysis of the harmonic and interharmonic contribution of EAF in the distribution system by using spectrogram successfully implemented in this study. From the analysis, the spectrogram succeeds in distinguishing the harmonic and interharmonic components. In the meantime, the THD(t) and TnHD(t) indices of the signals are calculated using the signal parameters that been obtained from the TFR. The results show that the spectrogram is a fast and accurate in identifying the harmonic and interharmonic contribution. Hence, the spectrogram is an appropriate technique to be implemented for analyzing the harmonic and interharmonic contribution of the EAF. 


\section{ACKNOWLEDGEMENTS}

This research is supported by Advanced Digital Signal Processing Laboratory (ADSP Lab). Special thanks also to the Faculty of Electrical Engineering and Engineering Technology of Universiti Teknikal Malaysia Melaka (UTeM), Center for Robotics and Industrial Automation (CeRIA) of UTeM, Ministry of Higher Education Malaysia (MOHE) and Ministry of Science, Technology and Innovation (MOSTI) for giving their cooperation and funding for this research with grant number 06-01-14-SF00119 L00025. Their support is gratefully acknowledged.

\section{REFERENCES}

[1] M. T. Esfahani and B. Vahidi, "A Probabilistic Three-Phase Time Domain Electric Arc Furnace Model based on analytical method," vol. 47, no. 1, pp. 1-10, 2015.

[2] T. M. O. N. Aye and S. O. E. W. I. N. Naing, "Harmonics Evaluation Generated By Electric Arc," no. 5, pp. 17-22, 2015.

[3] Y. Djeghader and H. Labar, "Improvement Of Power Quality In Electric Arc Furnace Operation Case Harmonics," pp. 5-9.

[4] Y. H. L. Djeghader, "Investigation of Voltage Unbalance Problems In Electric Arc Furnace Operation Model," no. April, 2016.

[5] Abidullah NA, Peng GZ, Abdullah AR. A new two points method for identify dominant harmonic disturbance using frequency and phase spectrogram. Int. Rev. Electr. Eng. 2014;9(2):453-9.

[6] Victor LR, Jidin A, Karim KA, Sutikno T, Sundram R, Jopri MH. Improved Torque Control Performance of Direct Torque Control for 5-Phase Induction Machine. International Journal of Power Electronics and Drive Systems. 2013 Dec 1;3(4):391.

[7] Bhonsle, Deepak C., and Ramesh B. Kelkar. "New time domain electric arc furnace model for power quality study." Power Electronics (IICPE), 2014 IEEE 6th India International Conference on. IEEE, 2014.

[8] A. Medina, P. Ribeiro, W. Xu, K. L. Lian, G. W. Chang, V. Dinavahi, and N. R. Watson, "Harmonic Analysis in Frequency and Time Domain," vol. 28, no. 3, pp. 1813-1821, 2013.

[9] S. K. Ojha, P. A. K. Nadir, M. Chauhan, and A. Kumar, "Identification and Minimization of Harmonics in Power System Networks,” Int. J. Emerg. Technol. Adv. Eng., vol. 4, no. 1, 2014.

[10] [S. A. A. M. Z. A. P. M. A. S. M. Khokhar, "A new optimal feature selection algorithm for classification of power quality disturbances using discrete wavelet transform and probabilistic neural network," Measurement, vol. 95, pp. 246-259, 2017.

[11] S. K. Singh, N. Sinha, A. K. Goswami, and N. Sinha, "Electrical Power and Energy Systems Several variants of Kalman Filter algorithm for power system harmonic estimation,” Int. J. Electr. Power Energy Syst., vol. 78, pp. 793-800, 2016.

[12] N.H.T Ahmad, A.R Abdullah, N.A Abidullah, "Analysis of Power Quality DIsturbances Using Spectrogram and STransform,” Int. Rev. Electr. Eng., vol. 9, 2014

[13] [N. M. Kassim, A. R. Abdullah, A. Fazliana, A. Kadir, and N. H. Shamsudin, "Harmonics Source Identification Analysis Using Spectrogram for Rectifier Load," J. Telecommun. Electron. Comput. Eng., vol. 8, no. 2, pp. 41-46, 2015.

[14] R. H. G. Tan and V. K. Ramachandaramurthy, "A Comprehensive Modeling and Simulation of Power Quality Disturbances Using MATLAB / SIMULINK,” Power Qual. Issues Distrib. Gener. InTech, 2015., 2015.

[15] [N. M. Kassim, and N. A. Ngatiman, and M. R. Yusoff, "Localization of Multiple Harmonic Sources for Inverter Loads Utilizing Periodogram,” J. Teknol., vol. 8, no. 2, pp. 87-91, 2016.

[16] T. Sutikno, and M. F. Habban, "An Accurate Classification Method of Harmonic Signals in Power Distribution System by Utilising S-Transform," TELKOMNIKA (Telecommunication Comput. Electron. Control., vol. 15, no. $1,2017$.

[17] [Abdullah AR, Ahmad NS, Bahari N, Manap M, Jidin A. Short-circuit switches fault analysis of voltage source inverter using spectrogram. InElectrical Machines and Systems (ICEMS), 2013 International Conference on 2013 Oct 26 (pp. 1808-1813). IEEE.

[18] Abidullah NA, Abdullah AR, Sha'ameri AZ, Shamsudin NH, Ahmad NH. Real-Time Power Quality Disturbances Detection and Classification System World Applied Sciences Journal. 2014;32(8):1637-51.

[19] Abdullah AR, Abidullah NA, Shamsudin NH, Ahmad NH. Power Quality Signals Classification System Using Time-Frequency Distribution. In Applied Mechanics and Materials 2014 (Vol. 494, pp. 1889-1894). Trans Tech Publications.

[20] Abdullah AR, Abidullah NA, Shamsudin NH, Ahmad NH. Performance Verification of Power Quality Signals Classification System. InApplied Mechanics and Materials 2015 (Vol. 752, pp. 1158-1163). Trans Tech Publications. 